\title{
Article \\ Microstructure and Properties of the 308LSi Austenitic Steel Produced by Plasma-MIG Deposition Welding with Layer-by-Layer Peening
}

\author{
Tatyana Olshanskaya ${ }^{1}$, Dmitry Trushnikov ${ }^{1} \mathbb{D}$, Alyona Dushina ${ }^{1}$, Artur Ganeev ${ }^{2}$, Alexander Polyakov ${ }^{1,2}$ \\ and Irina Semenova $2, *$ (D) \\ 1 Department of Welding Engineering, Materials Engineering and Metrology, Perm National Research \\ Polytechnic University, 29 Komsomolsky pr., 614990 Perm, Russia; tvo66@mail.ru (T.O.); \\ trdimitr@yandex.ru (D.T.); amchik@list.ru (A.D.); alex-v.polyakov@mail.ru (A.P.) \\ 2 Institute of Physics of Advanced Materials, Ufa State Aviation Technical University, 12 K. Marx Str., \\ 450008 Ufa, Russia; artur_ganeev@mail.ru \\ * Correspondence: semenova-ip@mail.ru; Tel.: +7-9174129508
}

check for

updates

Citation: Olshanskaya, T.;

Trushnikov, D.; Dushina, A.; Ganeev,

A.; Polyakov, A.; Semenova, I.

Microstructure and Properties of the

308LSi Austenitic Steel Produced by

Plasma-MIG Deposition Welding

with Layer-by-Layer Peening. Metals 2022, 12, 82. https://doi.org/

$10.3390 /$ met12010082

Academic Editor: Xiangdong Gao

Received: 25 November 2021

Accepted: 25 December 2021

Published: 4 January 2022

Publisher's Note: MDPI stays neutral with regard to jurisdictional claims in published maps and institutional affiliations.

Copyright: (c) 2022 by the authors. Licensee MDPI, Basel, Switzerland. This article is an open access article distributed under the terms and conditions of the Creative Commons Attribution (CC BY) license (https:/ / creativecommons.org/licenses/by/ $4.0 /)$.

\begin{abstract}
This paper investigates the effect of cold working via layer-by-layer peening on the microstructure and properties of a 308LSi steel workpiece produced by the wire deposition welding with a consumable electrode following the principle of 3D printing. The microstructure, phase composition and mechanical properties of the metal are studied before and after the workpiece synthesis. In the microstructure of the workpieces produced by peening, there is, in addition to austenite, a small quantity of fine-dispersed carbides and residual $\delta$-ferrite in the interdendritic spaces. It is demonstrated that the use of layer-by-layer cold working in the process of deposition welding enables eliminating transcrystallization of the deposited metal, promotes an increase in the microstructure's degree of dispersion and a more uniform distribution of fine-dispersed carbides in the volume of the dendrites. It is found that these structural features of the deposited metal in the additive manufacturing of a workpiece with layer-by-layer peening lead to an enhancement of the strength characteristics as compared to the material produced by the conventional wire deposition welding. Meanwhile, the level of the ductility characteristics remains high.
\end{abstract}

Keywords: austenitic steel; additive manufacturing; Plasma-MIG; layer-by-layer peening; microstructure; mechanical properties

\section{Introduction}

The modern production of complex large-sized metallic products using conventional processes (casting, forging, stamping, etc.) faces major difficulties and requires large expenses for process planning. Additive manufacturing processes enable considerable acceleration of the process planning and reduction of the costs for the manufacture of finished products [1]. In particular, additive manufacturing (AM) processes are widely applied in the manufacture or repair of complex metallic products by means of local restoration by a metallic wire or powder [2-4]. Depending on the heat source, AM processes are divided into wire arc additive manufacturing (WAAM), laser powder bed fusion (LPBF) and electron-beam melting [3,4]. Compared to powder-based additive manufacturing processes, WAAM offers high deposition rates as well as enhanced material utilization [5].

The most widely applied processes where wires are used as filler materials are arc processes: argon-arc welding with consumable and non-consumable electrodes, current straight-polarity plasma welding with a non-consumable electrode. One of the new methods among AM processes is plasma deposition welding with a consumable electrode (plasma-metal inert gas welding) that combines consumable-electrode arc welding and plasma welding [6,7]. Plasma-metal inert gas (Plasma-MIG) welding can be defined as a 
combination of plasma arc welding (PAW) and gas-metal arc welding (GMAW) [8] within a single torch, where a filler wire is fed through the plasma nozzle orifice. The plasma MIG hybrid welding torch is coaxial with the MIG electrode placed in the center, and the ring electrode in which the plasma arc is generated at the circumference $[9,10]$. The use of two heat sources (a plasma arc from a non-consumable anode and an arc from a consumable electrode) enables regulation of the heat input into the products in a wide range, increases productivity to $10 \mathrm{~kg} / \mathrm{h}$ and above, and provides a high quality. The axial feed of a wire electrode excludes the use of the systems of wire feed orientation with respect to the welding trajectory. As a result, this process has a number of advantages: a high stability and performance of the deposition welding process, regulation of the deposition welding process parameters in a wide range, the absence of spattering, control of the filler metal droplet transfer, and so forth. Due to the reverse-polarity plasma arc, the process of the cathodic cleaning of the deposition welding zone is realized where oxide films are effectively broken and removed, the wetting and spreading of the deposited metal are improved [11,12].

Many studies in the area of additive manufacturing are focused on a different series of steels, considering the fact that almost $80 \%$ (weight percent) of all metallic parts for engineering applications are made of steel [1-4,13]. Most often used in AM are austenitic steels. They have the same problems common for materials synthesized by additive manufacturing, related to residual stresses, anisotropy and pore formation [13]. The use of a wire filler material does not fully eliminate these drawbacks, which affects the strength and fatigue characteristics of a metal, as well as its corrosion resistance. In the present study, it is proposed to solve this problem by means of combining several processes where each layer of deposited metal after cooling is subjected to work hardening. Such plastic deformation treatment is known and applied for welded products with a view to increase their service life [14,15]. It was shown in [16-18], using several alloys as examples, that the use of layer-by-layer peening during the additive manufacturing of a workpiece reduces stresses, decreases grain size and, as a consequence, increases the mechanical characteristics to the level of the basic metal, reduces the metal's porosity and anisotropy. In the article [19] there was also shown a significant decrease in the anisotropy of the mechanical properties when layer-by-layer shot peening was applied. This approach was used in the present study during the wire plasma deposition welding of workpieces from the 308LSi austenitic steel. The aim of this study was to investigate the effect of layer-by-layer peening on the microstructure, phase composition and mechanical properties of the workpieces produced by the Plasma-MIG hybrid welding.

\section{Materials and Methods}

The OK Autrod 308LSi ESAB welding wire was used to produce the pilot workpieces. According to EN ISO 14343-2017, the material's yield strength is $400 \mathrm{MPa}$. The wire's chemical composition is given in Table 1 . The material of this chemical composition refers to austenitic stainless steels. The wire's ferrite number (FN) is 8 , which denotes that the content of the ferritic phase in the deposited metal is within a range of $3-8 \%(\sim 4.5 \%)$.

Table 1. Chemical composition (wt.\%) of the 308LSi wire according to EN ISO 14343-2017.

\begin{tabular}{ccccccc}
\hline $\mathbf{C}$ & $\mathbf{M n}$ & $\mathbf{S i}$ & $\mathbf{C r}$ & $\mathbf{N i}$ & $\mathbf{P}$ & $\mathbf{S}$ \\
\hline$\geq 0.03$ & $1.50-2.10$ & $0.65-1.00$ & $19.5-21.0$ & $9.0-11.0$ & $\geq 0.030$ & $\geq 0.020$ \\
\hline
\end{tabular}

The deposition welding was carried out using a plasma device for Plasma-MIG deposition welding designed at Perm National Research Polytechnic University. The principle of the facility is shown in Figure 1. A KEDR-400 power supply was used as the power supply for the consumable electrode, and a Kedr Arc-319 power supply for TIG welding was used as the power supply for the plasma arc. 


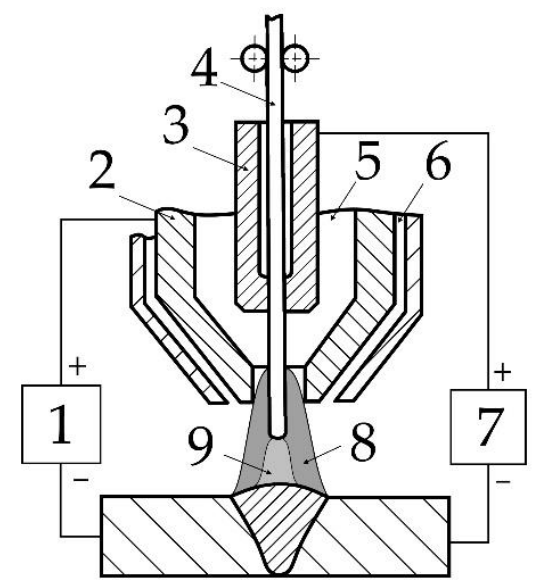

Figure 1. Principle of plasma arc welding (deposition welding) with a consumable electrode-PlasmaMIG: 1-plasma arc power supply; 2-non-consumable electrode; 3-contact tip; 4-consumable electrode; 5-plasma gas; 6-shielding gas; 7-power supply for the consumable electrode arc; 8-plasma arc; 9-consumable electrode arc.

The Plasma-MIG layer-by-layer depositions of wire material and deformation treatment are implemented on one platform using a CNC machine with an integral SA7401H AIRPRO air hammer manufactured by Airpro Industry Corp. (New Taipei, Taiwan). The principle of the facility is shown in Figure 2.

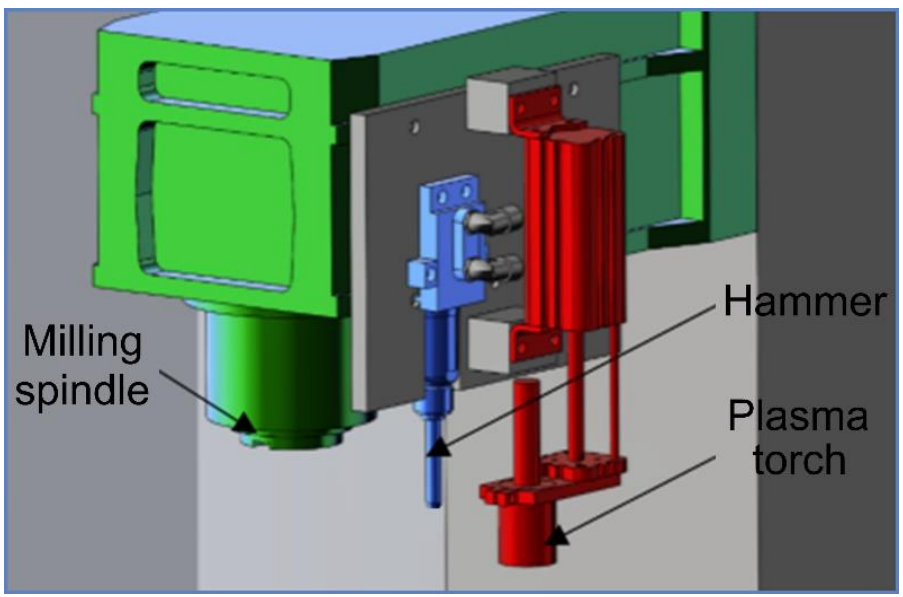

Figure 2. Principle of the facility for implementing Plasma-MIG hybrid welding and layer-bylayer peening.

The deposition welding of the walls with and without interpass work hardening (peening) was carried out via the selected deposition regime: plasma arc current $\mathrm{I}_{\mathrm{a}}=120 \mathrm{~A}$; consumable electrode arc current $\mathrm{I}_{\mathrm{e}}=210 \mathrm{~A}$; arc voltage $\mathrm{U}=23-24 \mathrm{~V}$; wire feed speed $V_{\text {wire }}=6.6 \mathrm{~m} / \mathrm{min}$; torch movement speed $\mathrm{V}_{\text {dep }}=90 \mathrm{~cm} / \mathrm{min}$; volume of argon supplied to the welding torch $Q_{\text {shield }}=7.5 \mathrm{~L} / \mathrm{min}$; volume of argon supplied to plasma forming nozzle $\mathrm{Q}_{\mathrm{pl}}=2.5 \mathrm{~L} / \mathrm{min}$. Peening was carried out via a previously selected regime: air hammer movement speed $V_{\text {ham }}=100 \mathrm{~mm} / \mathrm{min}$ (linear number of strokes $\mathrm{N} / \mathrm{L}=28.2$ strokes $/ \mathrm{mm}$ at the standard hammer stroke frequency $\mathrm{N}=2820$ strokes $/ \mathrm{min}$ ); the hammer tip was a semisphere with a radius of $R=20 \mathrm{~mm}$; stroke energy $\mathrm{E}=19.74 \mathrm{~J}$. The hammer's pressing force created by the air cylinder was $300 \mathrm{~N}$. The temperature at which the peening of the deposited layers was conducted was $\mathrm{T}=250-300^{\circ} \mathrm{C}$.

Workpiece samples for the study of the structure and mechanical characteristics of the deposited metal were produced in the form of a flat wall (Figure 3), where $X$ is the horizontal direction along the deposition direction, and $\mathrm{Z}$ is the vertical. 


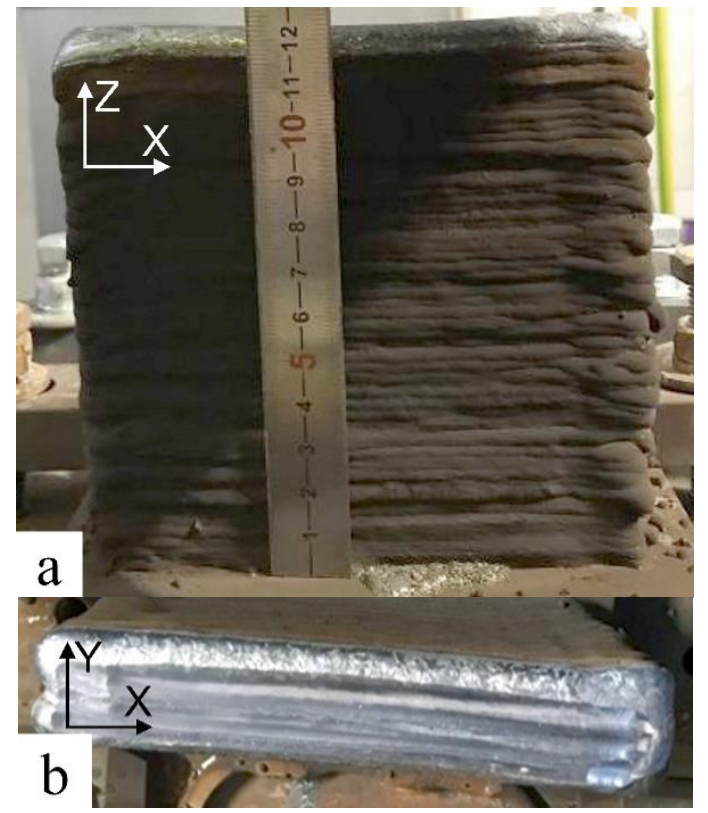

Figure 3. View of the workpiece: (a) side view, $X Z$; (b) the view from above $X Y$.

Microstructural studies were performed for the polished sections cut out in the transverse and longitudinal directions of the deposition welding of the wall workpiece. To reveal the microstructure, Vasiliev's chemical agent was used to treat the polished sections (hydrochloric acid $500 \mathrm{~mL}$, sulphuric acid $250 \mathrm{~mL}$, blue vitriol $100 \mathrm{~g}$, water $500 \mathrm{~mL}$ ). The studies were conducted on an Altami CM0745-T stereomicroscope (LLC Altami, Saint Petersburg, Russia) and an Altami MET 1T inverted light microscope (LLC Altami, Saint Petersburg, Russia) with a magnification up to $1000 \times$ using the Altami Studio 3.5 software (LLC Altami, Saint Petersburg, Russia). To study the microstructure and determine the local chemical composition of the phases, we used two scanning electron microscopes. A JEOL JSM 6490 microscope (JEOL Ltd., Tokyo, Japan) with an Inca X-sight Oxford Instruments attachment (JEOL Ltd., Tokyo, Japan) for local X-ray spectral microanalysis was used at $20 \mathrm{kV}$ and a HITACHI S-3400N high-resolution (3-10 nm) scanning electron microscope (Hitachi Ltd., Tokyo, Japan) equipped with a Bruker EDS XFlash Detektor (Bruker Corp., Billerica, MA, USA) 4010 was used at $5 \mathrm{kV}$.

The phase composition of the samples was studied using a Shimadzu XRD-7000 X-ray diffractometer (Shimadzu, Kyoto, Japan). To separate the $\mathrm{K}_{\beta}$ component of $\mathrm{X}$-ray radiation, a monochromator was used during the analysis. The $\mathrm{X}$-ray photography conditions were as follows: the range of the scan angle $2 \theta$ from 40 to $120 \mathrm{deg}$, $\mathrm{Cu}$ X-ray tube, tube voltage $30 \mathrm{kV}$, tube current $30 \mathrm{~mA}$, scan speed $1 \mathrm{deg} / \mathrm{min}$, scan step $0.01 \mathrm{deg}$, DS $1 \mathrm{deg}$, SS $1 \mathrm{deg}$, RS $0.15 \mathrm{~mm}$. The X-ray diffraction patterns were processed using the PANalytical X'Pert HighScore Plus Ver.2.1 software (Malvern Panalytical Ltd., Malvern, UK). The phase composition of the samples under analysis was determined using the ICDD PDF-2 Release 2012 database.

Hardness was tested by the Vickers method using an automated micro- and microhardness tester Emco-Test Durascan 50 (EMCO-TEST Prüfmaschinen GmbH, Kuchl, Austria), ser. No. 119, under a load of $100 \mathrm{~g}$. One hundred measurements were made in the form of a $5 \times 20$ net: 5 width measurements with a step of $0.1 \mathrm{~mm}$ and 20 depth measurements with a step of $0.05 \mathrm{~mm}$.

To find the mechanical properties, samples were cut out from the walls produced by deposition welding in accordance with Figure 4. 

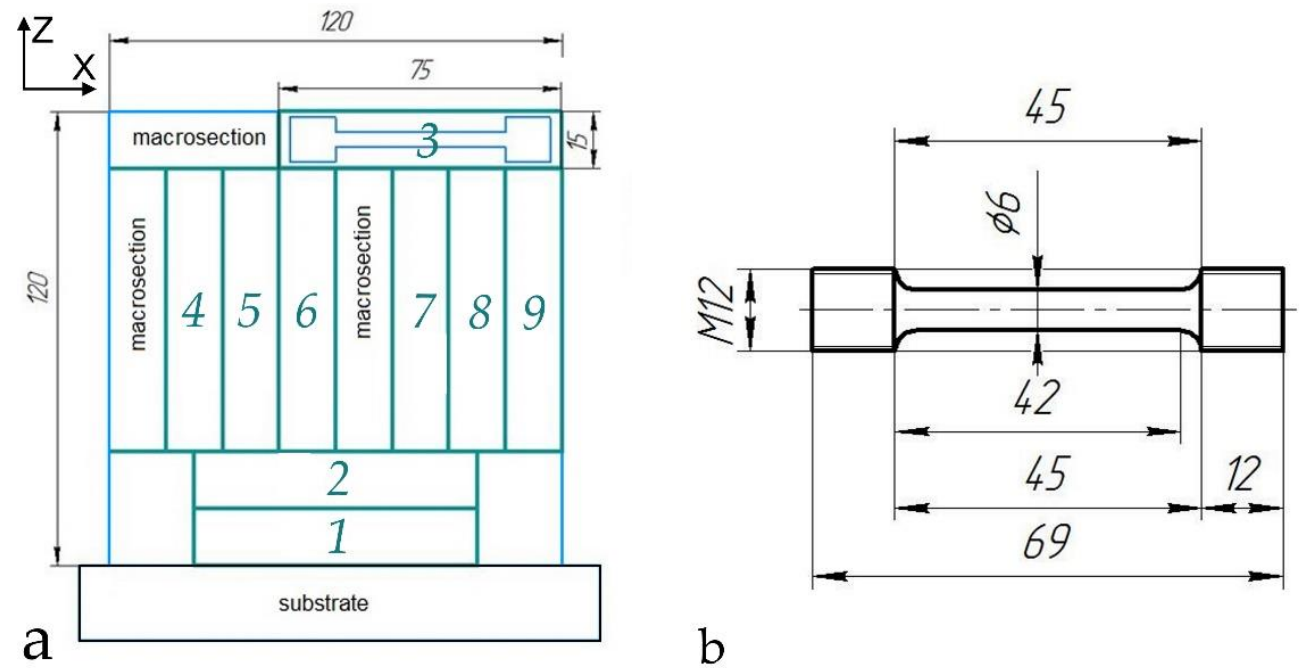

Figure 4. Plan of sampling sites for examination and a scheme for cutting out samples for mechanical tests (a) and the drawing of the tensile specimen in millimeters (b).

The largest variation in characteristics during additive growth is usually observed for samples in the vertical direction. So, three specimens and six specimens in the vertical have been tested for the tensile strength for each wall. Tensile tests were performed at room temperature with a strain rate of $1 \times 10^{-3} \mathrm{~s}^{-1}$ using an Instron 8801 servohydraulic system (Instron, Norwood, MA, USA) on standard (ISO 6892-1:2016) samples with a diameter of $5 \mathrm{~mm}$ and a gauge length of $25 \mathrm{~mm}$ (Figure $4 \mathrm{~b}$ ).

\section{Results}

\subsection{Macrostructure and Microstructure}

The macrostructure of the samples in the longitudinal and transverse sections is shown in Figure 5. Multi-layer deposition welding without layer-by-layer peening produces a macrostructure characteristic of oriented metal transcrystallization, where grains of a columnar shape grow through several deposited layers in the direction opposite to the maximum heat removal. In this crystallization, during the cooling of the liquid metal of a deposited layer the melted grains of a previous layer become crystallization centers, and further grain growth occurs with the preservation of crystallographic orientation. As a result, long columnar grains are formed that grow through the deposited layers. In addition, clearly seen in the macrostructure of the metal deposited without layer-by-layer peening are boundaries between the layers with a thin transition zone (Figure 5a,b).

The macrostructure of the samples deposited with layer-by-layer peening lacks the features characteristic of metal transcrystallization. The boundaries between the deposited layers are best seen in the longitudinal section (Figure $5 \mathrm{~d}$ ).

Figure 6 presents the optical images showing the microstructure of the metal workpieces subjected to deposition welding with and without layer-by-layer peening. In both cases, the microstructure has a dendritic arrangement characteristic of the deposited metal of an austenitic steel [2]. For the sample without layer-by-layer peening, visible in Figure 6a are the columnar shape of the dendrites, fusion zones between the layers and the growth of dendrites through fusion zones characteristic of the workpiece macrostructure (see Figure $5 a, c)$. The microstructure of the metal deposited with layer-by-layer peening presented in Figure $6 \mathrm{~b}$ is characterized by equiaxed-shape dendrites with a small fraction of columnar dendrites in individual layers. 

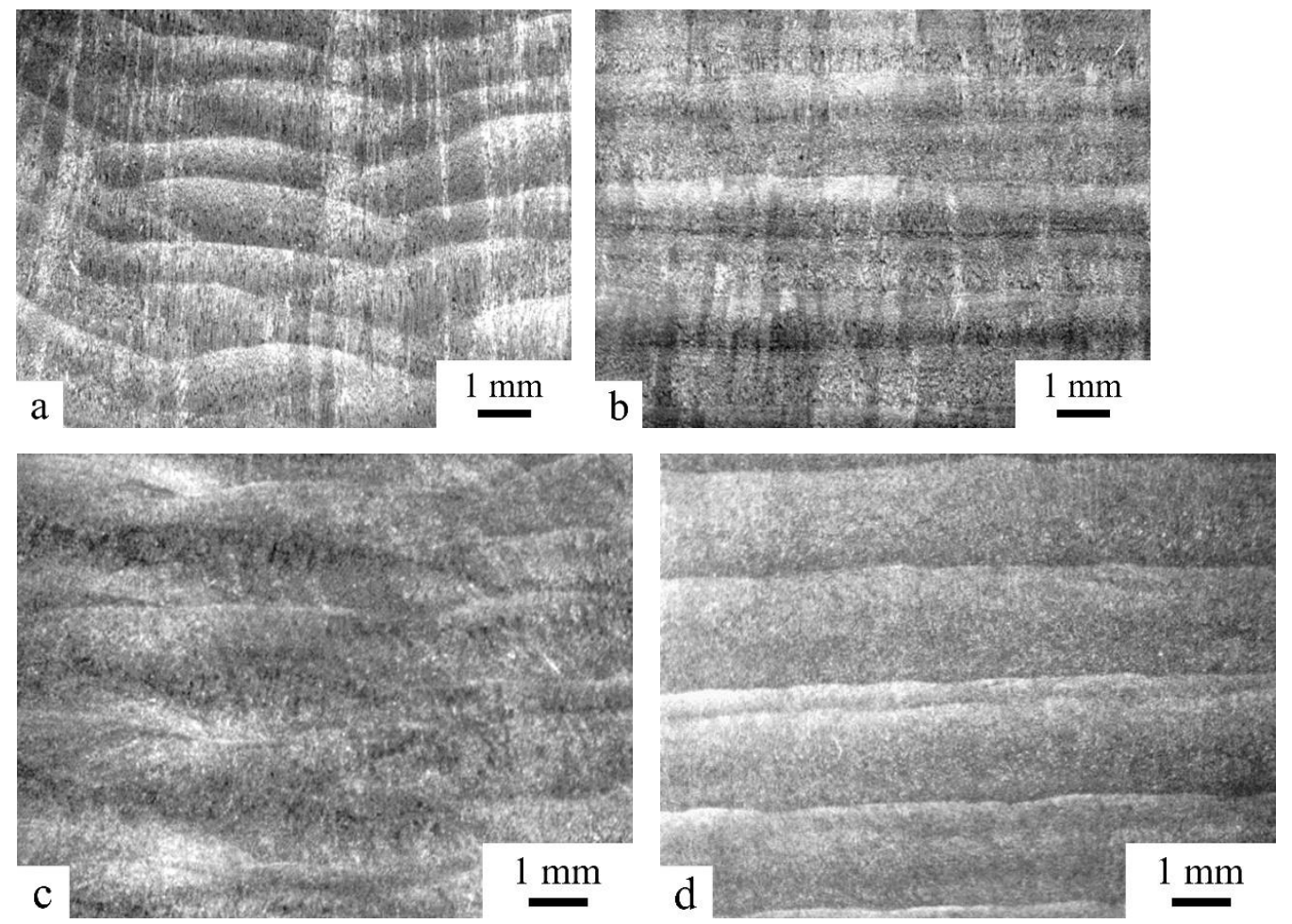

Figure 5. Macrostructure of the deposited metal: $(\mathbf{a}, \mathbf{b})$ - deposition welding without layer-by-layer peeing, (c,d)—deposition welding with layer-by-layer peening; $(\mathbf{a}, \mathbf{c})$ - transverse section, $(\mathbf{b}, \mathbf{d})$ longitudinal section.
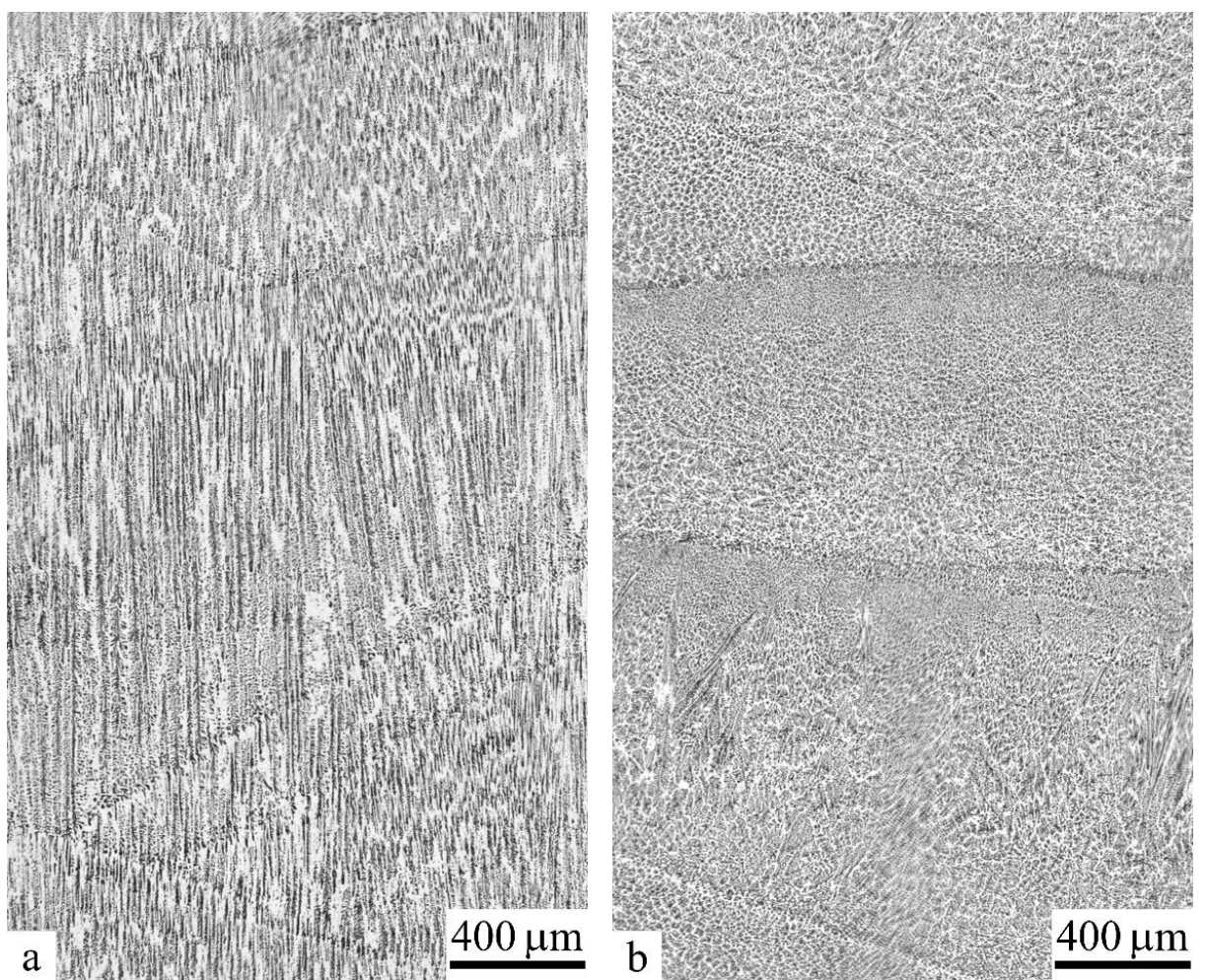

Figure 6. General view of the microstructure of the metal deposited without (a) and with (b) layerby-layer peening. 
Figure 7 shows the skeletal dendritic structure at a boundary between the deposited layers. It should be noted that the microstructure of the metal inside a layer in the workpieces produced without peening is characterized by a pronounced anisotropy and metallographic texture (Figure 7a), unlike the microstructure of the metal deposited with peening (Figure 7b).
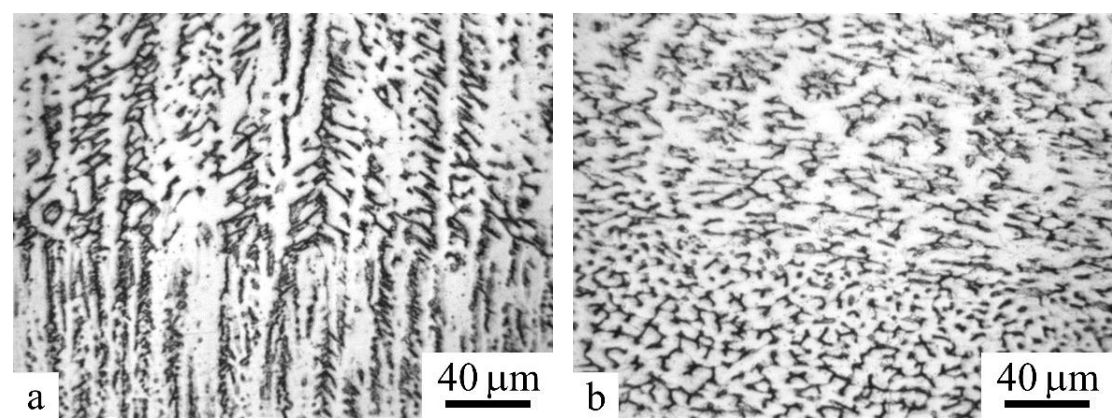

Figure 7. Microstructure of the metal at a boundary between the deposited layers in a sample produced without (a) and with (b) cold peening.

\subsection{Layer-by-Layer Chemical Analysis of the Workpieces}

Figure 8 shows the SEM images of the structure of the samples at 2500× magnification and the direction of layer-by-layer local chemical analysis. Figure 9 shows the concentrations of the main alloying elements $\mathrm{Cr}$ and $\mathrm{Ni}$ in accordance with the scheme presented in Figure 8.

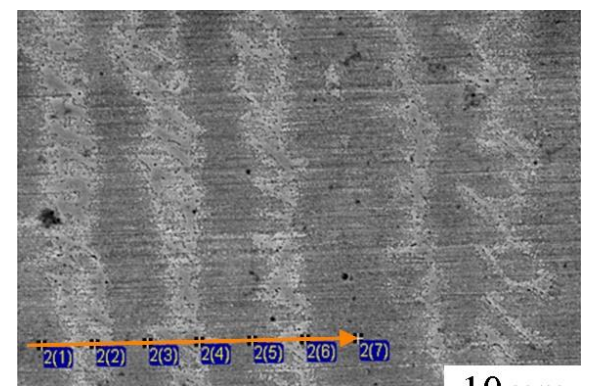

a
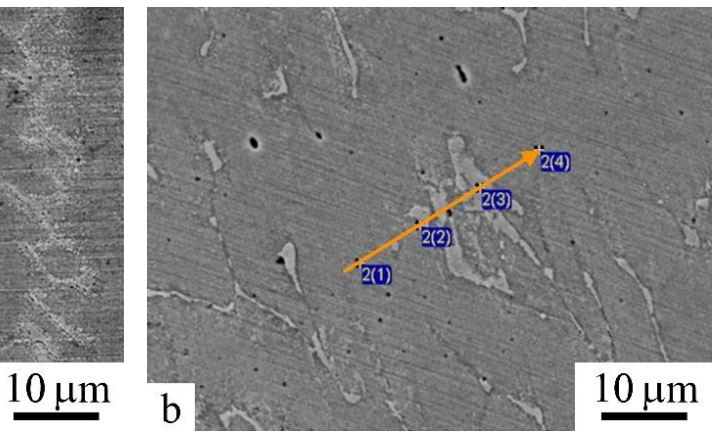

Figure 8. Microstructure of the deposited metal without (a) and with (b) layer-by-layer peening.
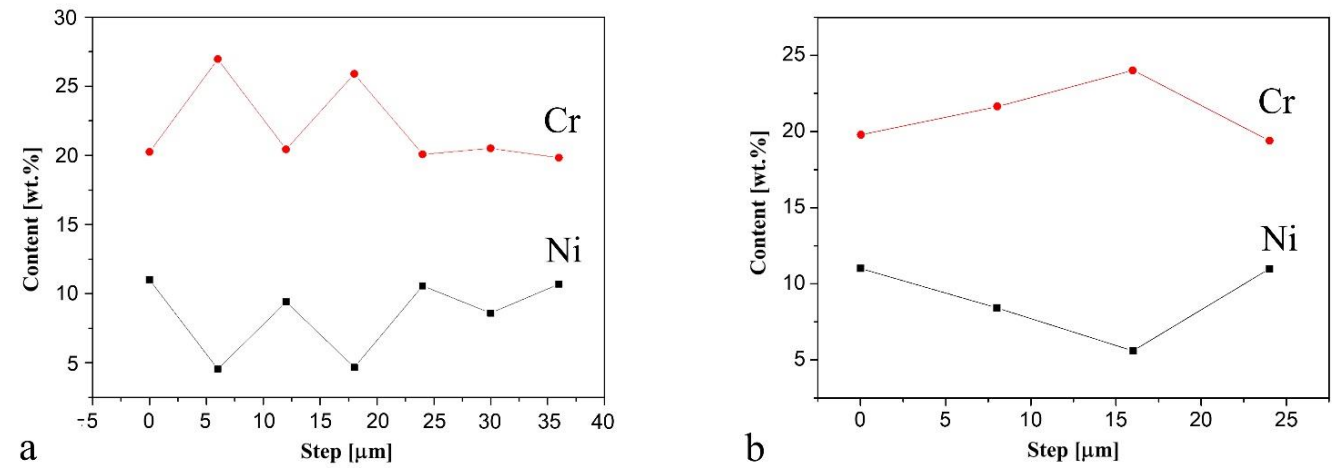

Figure 9. Distribution of the alloying elements (Cr, Ni) along the EDS lines: (a) deposition welding without peening; (b) deposition welding with peening. 
To analyze the chemical element distribution, successive accumulation of the X-ray spectrum along the lines marked in Figure 8 was carried out. Based on the results of the EDS analysis, line charts were built showing the variations of the local chemical composition (Figure 9).

It can be seen that the deposited metal is characterized by high gradients of the variation of $\mathrm{Cr}$ and $\mathrm{Ni}$ concentrations in the carbide phase. The local $\mathrm{Cr}$ concentration increases by $7 \%$ and reaches $27 \%$ wt., with the Ni concentration simultaneously decreasing by the same $7 \%$ in the interdendritic space (Figure $9 a$ ). Layer-by-layer peening leads to the formation of a developed network of fine precipitates with the $\mathrm{Cr}$ concentration increased to $25 \%$ that has a more blurred character (Figure $9 \mathrm{~b}$ ), which may be related to the resolution capability of the used detector. Mn and Si concentrations practically did not vary.

\subsection{Phase Composition of the Samples Subjected to Deposition Welding}

Figure 10 shows the X-ray diffraction patterns of the samples. The peaks in the diffraction pattern for the metal deposited without peening (1) coincide with peaks 2, 3 and 4 in the diffraction pattern for the metal deposited with layer-by-layer peening (2).

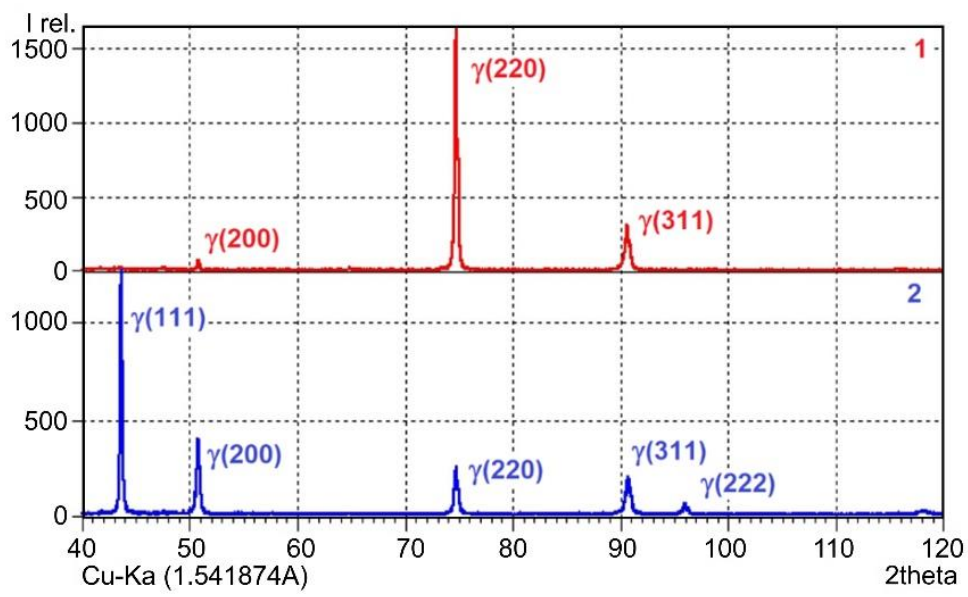

Figure 10. X-ray diffraction patterns for the steel samples after plasma deposition welding without layer-by-layer peening (line 1) and with layer-by-layer peening (line 2).

The X-ray diffraction patterns were processed using the PANalytical X'Pert HighScore Plus Ver. 2.1 software. The peaks in the diffraction patterns for both samples are characterized by the following phase composition: austenite; solid solution based on $\gamma$-Fe; complex carbides $\mathrm{Cr}_{2} \mathrm{Fe}_{14} \mathrm{C}$. A high intensity of the $\gamma$-Fe (220) peak in the sample produced by deposition welding without peening indicates the predominant crystallization of austenite dendrites in one crystallographic direction, which testifies to texture formation, which correlates with the transcrystalline character of the sample's macrostructure. For the metal produced with layer-by-layer peening, the peaks in the diffraction pattern correspond to the reflection angles from a larger number of crystallographic planes $\gamma$-Fe (Figure 10).

It should be noted that the sensitivity of XRD is reduced when a phase content is below $5 \%$, although a refection from $\delta$-Fe was found in both samples when the X-ray diffraction patterns were deciphered using the above-mentioned software. In sample 1, its intensity was very small, and in the X-ray diffraction pattern for sample 2 the $\gamma(111)$ peak apparently overlapped with the $\delta$-ferrite peak.

The microstructural studies of the workpieces performed using an optical microscope confirmed that, during the metal crystallization, not only was $\delta$-ferrite formed in interdendritic spaces, but also a small quantity of small-dispersed carbides. This was observed for both deposition welding without peening and deposition welding with peening (Figure 11a,b). It can be seen in Figure 11 that, in polarized light, the planar and isotropic structural constituents, such as austenite and ferrite, remain dark [20,21]. It can be noted 
that in the case of deposition welding with layer-by-layer peening, the quantity of carbide particles in interdendritic boundaries is somewhat larger than in the case of deposition welding without deformation, and they are more uniformly distributed (Figure 11b), which correlates with the distribution of $\mathrm{Cr}$ in the sample section (Figure $9 \mathrm{~b}$ ).
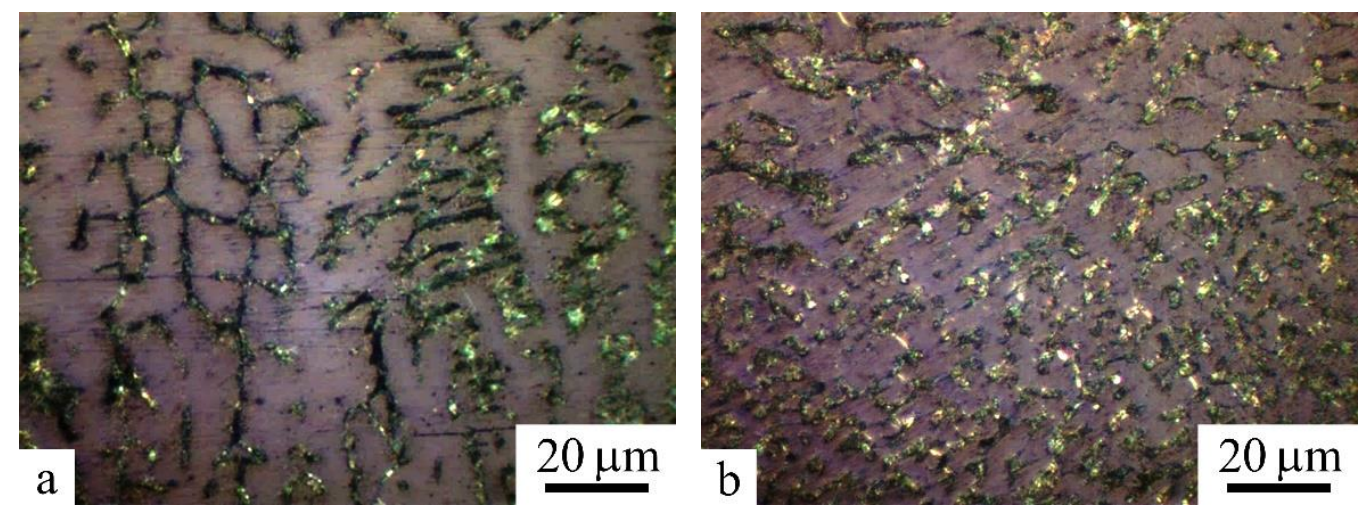

Figure 11. Microstructure inside a layer for the samples after deposition welding without (a) and with (b) layer-by-layer peening. Polarized light.

Figure 12 presents the SEM images showing the microstructure of the interdendritic space for the samples with and without layer-by-layer peening. In addition to austenite and skeletal $\delta$-ferrite, dispersed particles, presumably of carbides, are revealed (Figure 12c,d). In the metal produced by deposition welding without peening, carbides are larger in size (Figure 12a) than those in the metal produced by deposition welding with peening (Figure 12b). The chemical composition of the fine-dispersed particles determined with the use of an energy-dispersive spectrometer mounted on a scanning electron microscope with high resolution enables assuming that the particles (marked as an example in Figure 12c,d) represent carbide compounds with a complex composition.
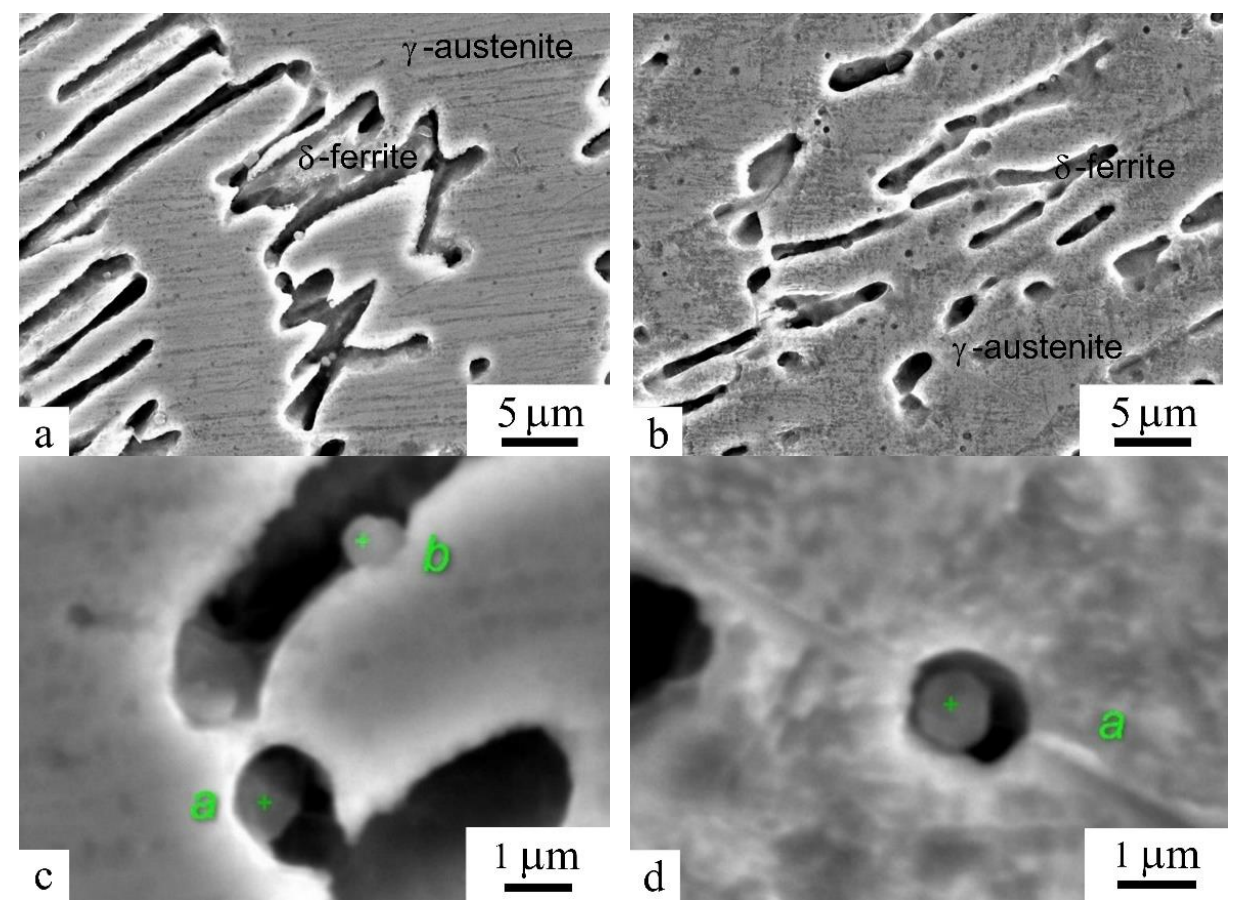

Figure 12. SEM images of the microstructure and carbide particles in the metal deposited without peening $(\mathbf{a}, \mathbf{c})$ and with peening $(\mathbf{b}, \mathbf{d})$. 


\subsection{Mechanical Properties of the Samples Produced by Deposition Welding}

The Vickers microhardness testing was performed in such a manner as to include the areas of the upper and lower layers. Based on the test results, microhardness maps were built. Figure 13 presents the microhardness test results. In the figure, the fusion zone is marked by a line, the values in depth (h) with a "-" sign correspond to the lower layer, those with a "+" sign correspond to the upper layer.
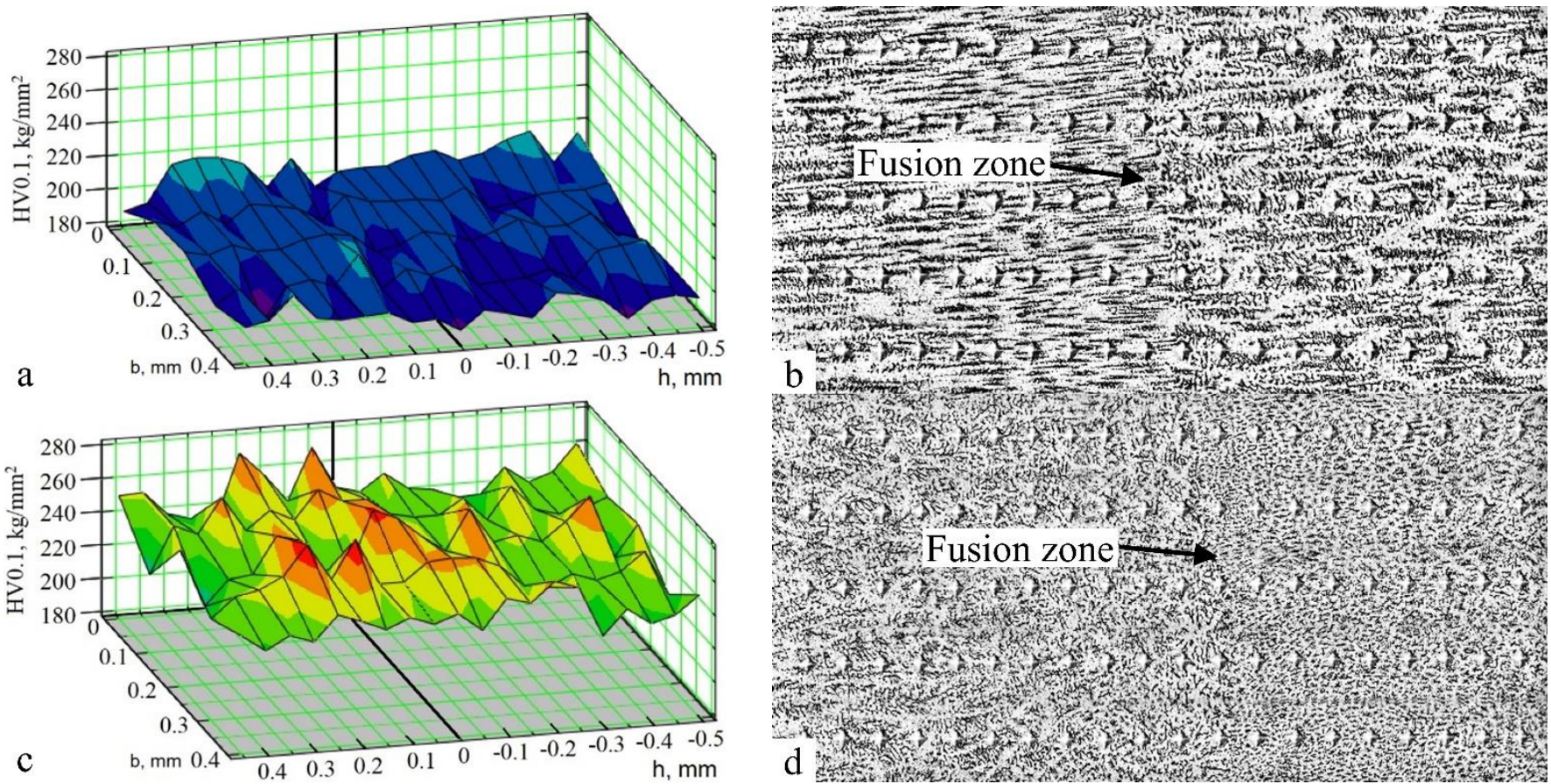

Figure 13. Microhardness maps for the transition zone between layers $(\mathbf{a}, \mathbf{c})$ and measurement examples (b,d): $(\mathbf{a}, \mathbf{b})$ - welding deposition without peening; $(\mathbf{c}, \mathbf{d})$-welding deposition with layerby-layer peening; h-measurements in layer depth, (b)-measurements in layer width.

The obtained measurement data were statistically processed, the results are presented in Table 2 and in Figure 14.

Table 2. Microhardness HV0.1 of the samples produced using different process variants.

\begin{tabular}{ccc}
\hline Values & $\begin{array}{c}\text { Without Layer-by-Layer } \\
\text { Deformation }\end{array}$ & $\begin{array}{c}\text { With Layer-by-Layer } \\
\text { Deformation }\end{array}$ \\
\hline Average value & 201.36 & 250 \\
Minimum value & 180 & 224 \\
Maximum value & 217 & 279 \\
o-Root-mean-square deviation & 7.16 & 11.35 \\
v-Variation coefficient $(\%)$ & 3.56 & 4.54 \\
\hline
\end{tabular}

The presented results demonstrate that when layer-by-layer cold peening is used, the total level of hardness increases by $50 \mathrm{HV}$, but a more uniform hardness distribution is observed in the case of deposition welding without peening.

The mechanical characteristics, obtained as a result of tensile tests, for the metal deposited using different process variants are presented in Table 3. For the sake of comparison, the table also lists the requirements to the mechanical properties specified for the metal deposited by 308LSi wire welding in accordance with EN ISO 14343-2017 and for the AISI 304 L steel produced by conventional methods in accordance with ASTM A240. Table 3 demonstrates that wire deposition welding with layer-by-layer peening increased strength while preserving high ductility. 

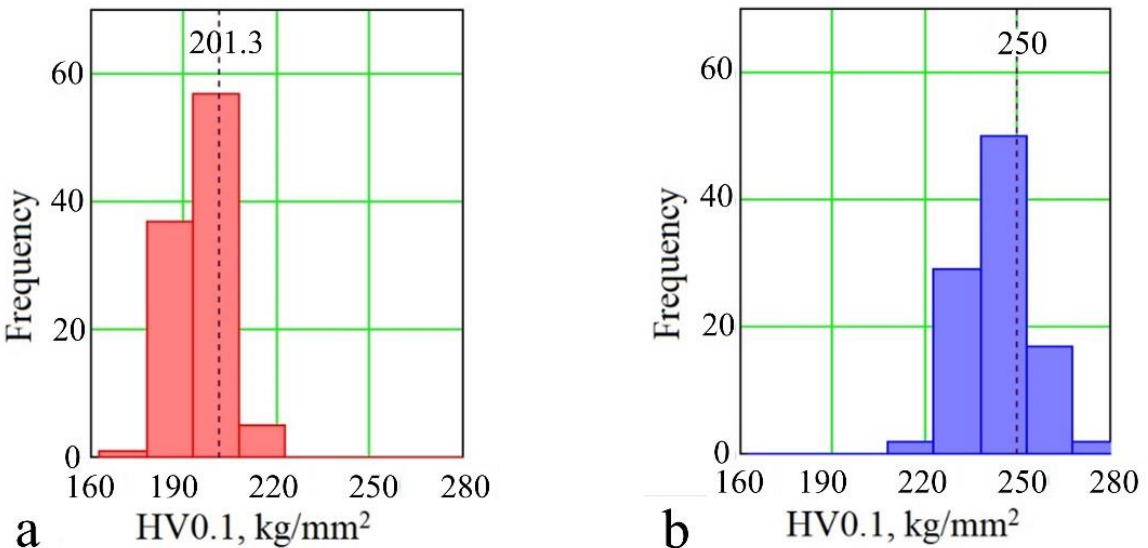

Figure 14. Diagrams of the frequency distribution of the microhardness values: (a)—deposition welding without peening; (b)—deposition welding with layer-by-layer peening.

Table 3. Results from the testing of the mechanical properties.

\begin{tabular}{|c|c|c|c|c|c|}
\hline Fabrication Method & $\begin{array}{l}\text { Specimen } \\
\text { Orienta- } \\
\text { tion }\end{array}$ & $\begin{array}{l}\text { UTS } \\
{[\mathrm{MPa}]}\end{array}$ & $\begin{array}{l}\text { YS0.2 } \\
{[\mathrm{MPa}]}\end{array}$ & $\begin{array}{c}\text { Elongation, } \\
\delta[\%]\end{array}$ & $\begin{array}{c}\text { Reduction } \\
\text { Area, } \psi[\%]\end{array}$ \\
\hline $\begin{array}{c}\text { Plasma-MIG } \\
\text { deposition welding }\end{array}$ & Z & $555 \pm 7$ & $295 \pm 5$ & $34 \pm 3$ & $72 \pm 10$ \\
\hline $\begin{array}{c}\text { Plasma-MIG } \\
\text { deposition welding }\end{array}$ & $x$ & $560 \pm 10$ & $300 \pm 10$ & $50 \pm 5$ & $60 \pm 5$ \\
\hline $\begin{array}{c}\text { Plasma-MIG } \\
\text { deposition welding } \\
\text { with layer-by-layer } \\
\text { peening }\end{array}$ & Z & $710 \pm 20$ & $550 \pm 30$ & $30 \pm 6$ & $50 \pm 2$ \\
\hline $\begin{array}{c}\text { Plasma-MIG } \\
\text { deposition welding } \\
\text { with layer-by-layer } \\
\text { peening }\end{array}$ & $\mathrm{X}$ & $740 \pm 20$ & $570 \pm 30$ & $36 \pm 1$ & $56 \pm 6$ \\
\hline $\begin{array}{l}\text { 308LSi according to } \\
\text { EN ISO 14343-2017 }\end{array}$ & - & 570 & 400 & 36 & - \\
\hline $\begin{array}{c}\text { AISI } 304 \text { L steel } \\
\text { according to ASTM } \\
\text { A240 (thick sheet) }\end{array}$ & - & $\geq 485$ & $\geq 170$ & 40 & - \\
\hline
\end{tabular}

\section{Discussion}

Based on the results of the study, the features of the formation of macro- and microstructure and phase composition in the workpiece from the 308LSi alloy produced by Plasma-MIG hybrid welding with the use of layer-by-layer cold working have been revealed.

First, in both cases a dendritic microstructure is formed, characteristic of layer-by-layer wire deposition welding of austenitic steels [2]. A difference in the shape of the dendrites was revealed. In particular, in the regular regime of deposition welding (without layer-bylayer peening) the dendrites are characterized by a columnar shape and grow through the fusion zone (Figure 6a). Such structures were observed in [2] during deposition welding by WAAM. The introduction of cold working after the cooling of a layer led to the formation of dendrites with predominantly a more equiaxed shape (Figure 6b). The microstructure of the metal inside the layer in the workpieces produced using peening is characterized by a less pronounced anisotropy and metallographic texture (Figure 7b). Apparently, during cold working, the level of stress and the dislocation density in the surface layer increase, 
which promotes a change in the direction of crystallite growth in the next layer and, as a consequence, a refinement of the microstructure.

Therefore, during the crystallization of a new deposited layer, the number of crystallization centers increases and, as a result, a more dispersed microstructure is formed than in the case of deposition welding without peening.

The studies of the phase composition of the metal produced via different regimes demonstrate that the crystallized metal consists of austenite and carbides that precipitated during cooling from the $\mathrm{Cr}$-rich austenite. In the $\mathrm{X}$-ray diffraction pattens of the samples produced using cold peening, peaks from $\delta$-ferrite are observed (Figure 10). It is known from the literature data $[22,23]$ that the crystallization of austenitic steels (like 308L) in a range of temperatures between the liquidus and the solidus occurs via the following mechanism: austenite is formed as the first phase, then eutectic ferrite precipitates in the interdendritic space. Eutectic ferrite is formed from the last portions of the $\mathrm{Cr}$ - and $\mathrm{Ni}$-rich liquid phase via the liquidation mechanism:

$$
\mathrm{L} \rightarrow \mathrm{L}+\gamma \rightarrow \mathrm{L}+\gamma+(\gamma+\delta)_{\text {eut }} \rightarrow \gamma+\delta_{\text {eut }}
$$

Correspondingly, the structure of the crystallized metal represents austentite's dendrites $(\gamma)$ and residual delta-ferrite $(\delta)$ at the boundaries of dendrites and cells. Normally, the content of residual $\delta$-ferrite in a deposited metal does not exceed $8 \%$ [23]. It can be assumed that residual $\delta$-ferrite is present in both samples produced with and without peening. Apparently, in both cases peaks in the X-ray diffraction pattens had low intensity. Meanwhile, according to [2] the content of residual $\delta$-ferrite under different parameters of the WAAM treatment of the $316 \mathrm{~L}$ steel was from $13 \%$ to $17 \%$.

The data of the X-ray phase analysis data correlate with the results of the microstructural studies on optical and scanning microscopes and indicate that, at the final stage of crystallization, carbide compounds precipitate from the last portions of the liquid phase in the layers deposited using both process variants. Apparently, the formation of finedispersed carbides may be associated with a continuous thermal cycle. It appears that, in the process of the deposition of a new layer, the preceding layer experiences a hightemperature heating below the solidus temperature. Such heating may promote carbide precipitation in interdendritic spaces enriched with carbon and chromium, predominantly at the boundaries between dendrites and cells. Due to the fact that, in the case of deposition welding with layer-by-layer cold working, a more dispersed structure is formed, the carbide size is smaller and they are more uniformly distributed in the structure (Figure 11).

The results of the microhardness testing of the samples produced by both variants of deposition welding show that when layer-by-layer cold peening is used, the total level of hardness increases by $50 \mathrm{HV}$ due to an increase in the microstructure's degree of dispersion. At the same time, a less uniform hardness distribution is observed in the case of deposition welding with peening (Figure 14). This could evidently be attributed to the different degrees of dispersion of the microstructure inside a layer and in the near-boundary regions corresponding to the surface of the filler wire subjected to cold working (Figure 7b). Such a regularity was observed earlier in [16].

The tensile mechanical tests of the samples demonstrate that the use of layer-by-layer cold peening during the plasma wire deposition welding Plasma-MIG leads to the enhancement of the strength characteristics while preserving the ductility characteristics at a high level as compared to deposition welding without peening (UTS 710 and $555 \mathrm{MPa}$, respectively). The anisotropy of properties does not increase either. The use of the subsequent heat treatment of the obtained samples would perhaps additionally reduce the scatter of the characteristic values in the vertical and horizontal directions, which will be necessarily investigated in subsequent works. It should be noted that the ultimate tensile strength of the $316 \mathrm{~L}$ steel metal produced by the conventional WAAM method is within a range of 520-570 MPa [2], which correlates with the level of strength of the sample produced in the present work without layer-by-layer peening (598 MPa). 
Thus, the results obtained in the present study demonstrate that the Plasma-MIG hybrid process that combines arc deposition welding with a consumable electrode and plasma deposition welding is a promising method for manufacturing large-sized parts. The introduction of deformation treatment in the process of the layer-by-layer synthesis of a workpiece leads to grain size reduction, a decrease in the anisotropy of the macroand microstructure and, consequently, an increase in the mechanical characteristics of a workpiece. This research area is in its development stage and opens prospects for producing workpieces with a minimum machining allowance and high service characteristics. At the same time, its wide application in industry requires solving various materials-science and processing tasks. This includes the tasks of providing the precision of a workpiece and the specified structure and properties of a metal, such as fusion penetration depth, area of the fusion zone between layers, rates of metal heating and cooling, time for which a metal is in the molten state, chemical composition of metal layers, loss of alloying elements, and so forth. It should be noted that layer-by-layer shot peening reduces the productivity of the process (by a factor of 1.5-2), but this fact can fade into the background in the manufacture of critical products, when the level and reproducibility of the mechanical properties of the material of the part are of paramount importance.

\section{Conclusions}

The following conclusions can be made based on the results of the study of the workpieces produced from the 308LSi steel by Plasma-MIG wire deposition welding and Plasma-MIG wire deposition welding with layer-by-layer peening:

1. In the process of Plasma-MIG deposition welding, a columnar dendritic structure is formed that is characteristic of oriented metal transcrystallization with a specific crystallographic orientation. The use of layer-by-layer cold peening during PlasmaMIG deposition welding enables eliminating transcrystallization of the deposited metal and promotes an increase in the fraction of equiaxed dendrites and the degree of dispersion of the microstructure.

2. During Plasma-MIG deposition welding and Plasma-MIG deposition welding with layer-by-layer cold peening, in addition to austenite, a certain quantity of finedispersed carbides and residual $\delta$-ferrite form in the interdendritic space. A more uniform distribution of fine-dispersed carbides in the volume of the dendrites is observed in the case of deposition welding with layer-by-layer peening.

3. It is shown that the use of layer-by-layer cold peening during plasma wire deposition welding leads to an increase in the strength characteristics from 555 to $710 \mathrm{MPa}$, while preserving the ductility characteristics at a high level.

Author Contributions: Conceptualization, T.O. and D.T.; Investigation, A.D., A.G. and A.P.; Methodology, T.O. and I.S.; Writing-original draft, T.O.; Writing-review \& editing, D.T. and I.S. All authors have read and agreed to the published version of the manuscript.

Funding: This research was funded by Russian Science Foundation (RSF), grant number 21-19-00715 "Control of microstructure, strength, residual stresses and geometry distortions in hybrid additive manufacturing" (Agreement No. 21-19-00715 dated 20 March 2021).

Institutional Review Board Statement: Not applicable.

Informed Consent Statement: Not applicable.

Data Availability Statement: Not applicable.

Acknowledgments: The authors are grateful to the Center for Common Use "Nanotech" of Ufa State Aviation Technical University.

Conflicts of Interest: The authors declare no conflict of interest. 


\section{References}

1. DebRoy, T.; Wei, H.L.; Zuback, J.S.; Mukherjee, T.; Elmer, J.W.; Milewski, J.O.; Beese, A.M.; Wilson-Heid, A.; De, A.; Zhang, W. Additive manufacturing of metallic components_Process, structure and properties. Prog. Mater. Sci. 2018, 92, 112-224. [CrossRef]

2. Long, P.; Wen, D.; Min, J.; Zheng, Z.; Li, J.; Liu, Y. Microstructure Evolution and Mechanical Properties of a Wire-Arc Additive Manufactured Austenitic Stainless Steel: Effect of Processing Parameter. Materials 2021, 14, 1681. [CrossRef] [PubMed]

3. Ding, D.; Pan, Z.; Cuiuri, D.; Li, H. Wire-feed additive manufacturing of metal components: Technologies, developments and future interests. Int. J. Adv. Manuf. Technol. 2015, 81, 465-481. [CrossRef]

4. Wu, B.; Pan, Z.; Ding, D.; Cuiuri, D.; Li, H.; Xu, J.; Norrish, J. A review of the wire arc additive manufacturing of metals: Properties, defects and quality improvement. J. Manuf. Process. 2018, 35, 127-139. [CrossRef]

5. Köhler, M.; Fiebig, S.; Hensel, J.; Dilger, K. Wire and Arc Additive Manufacturing of Aluminum Components. Metals 2019, 9, 608. [CrossRef]

6. Lee, H.; Park, S.; Kang, C.-Y. Effect of plasma current on surface defects of plasma-MIG welding in cryogenic aluminum alloys. J. Mater. Process. Technol. 2015, 223, 203-215. [CrossRef]

7. Lee, H.-K.; Chun, K.-S.; Park, S.-H.; Kang, C.-Y. Control of surface defects on plasma-MIG hybrid welds in cryogenic aluminum alloys. International. Int. J. Nav. Archit. 2015, 7, 770-783. [CrossRef]

8. Guo, Y.; Pan, H.; Ren, L.; Quan, G. An investigation on plasma-MIG hybrid welding of 5083 aluminum alloy. Int. J. Adv. Manuf. Technol. 2018, 98, 1433-1440. [CrossRef]

9. Mamat, S.; Afandi, A.A.M.; Abu Bakar, M.B.; Masri, M.N.; Mohamed, M.; Razab, M.K.A.A.; Tanaka, M. Effect of Plasma Flow in Plasma MIG Welding Process to the Microstructure Refinement at Heat Affected Zone of As-Welded Carbon Steel. Mater. Sci. Forum 2020, 1010, 15-20. [CrossRef]

10. Harris, I.D. Plasma-MIG Welding, Welding, Brazing, and Soldering. In ASM Handbook; Thomas, D.L.O., Siewert, A., Glen, S.L., Edwards, R., Eds.; ASM International: Cleveland, OH, USA, 1993; Volume 6, pp. 223-225.

11. Shchitsyn, Y.D.; Terentev, S.A.; Neulybin, S.D.; Artyomov, A.O. Formation of 04Cr18Ni9 steel structure and properties during additive manufacturing of blanks. Int. J. Adv. Manuf. Technol. 2019, 102, 3719-3723. [CrossRef]

12. Blakhyna, I. Investigation of surfaced press molds made its working resource. Technol. Audit Prod. Reserves 2017, 3, 34-38. [CrossRef]

13. Haghdadi, N.; Laleh, M.; Moyle, M.; Primig, S. Additive manufacturing of steels: A review of achievements and challenges. J. Mater. Sci. 2021, 56, 64-107. [CrossRef]

14. Knysh, V.V.; Solovej, S.A.; Kuzmenko, A.Z. Effectiveness of strengthening butt welded joints after long-term service by highfrequency mechanical peening. Paton Weld. J. 2014, 11, 42-45. [CrossRef]

15. Lu, J.Z.; Luo, K.Y.; Zhang, Y.K.; Sun, G.F.; Gu, Y.Y.; Zhou, J.Z.; Ren, X.D.; Zhang, X.C.; Zhang, L.F.; Chen, K.M.; et al. Grain refinement mechanism of multiple laser shock processing impacts on ANSI 304 stainless steel. Acta Mater. 2010, 58, 5354-5362. [CrossRef]

16. Martina, F.; Williams, S.W.; Colegrove, P.A. Improved microstructure and increased mechanical properties of additive manufacture produced Ti-6Al-4V by interpass cold rolling. In Proceedings of the 24th International Solid Freeform Fabrication Symposium, Austin, TX, USA, 12-14 August 2013.

17. Baranov, V.N.; Sidelnikov, S.B.; Bezrukikh, A.I.; Zenkin, E.Y. Study of the rolling regimes and mechanical properties of the cold-rolled, annealed and welded semi-products from Al-Mg pilot alloys sparingly alloyed with Sc. Tsvetnye Met. 2017, 9, 91-96. (In Russian) [CrossRef]

18. Panin, V.E.; Kablov, E.N.; Pleshanov, V.S.; Klimenov, V.A.; Ivanov, Y.F.; Pochivalov, Y.I.; Kibitkin, V.V.; Napryushkin, A.A.; Nekhoroshkov, O.N.; Lukin, V.I.; et al. Effect of ultrasonic impact treatment on the structure and fatigue resistance of VKS-12 high-strength steel welds. Fiz. Mezomekhanika 2006, 9, 85-96. (In Russian)

19. Shchitsyn, Y.; Kartashev, M.; Krivonosova, E.; Olshanskaya, T.; Trushnikov, D. Formation of Structure and Properties of Two-Phase Ti-6Al-4V Alloy during Cold Metal Transfer Additive Deposition with Interpass Forging. Materials 2021, 14, 4415. [CrossRef]

20. Brooks, J.A.; Williams, J.C.; Thompson, A.W. Microstructural origin of the skeletal ferrite morphology of austenitic stainless steel welds. Metall. Trans. A 1983, 14, 1271-1281. [CrossRef]

21. Anisovich, A.G.; Rumyantseva, I.N. Practice of Metallographic Studies of Metals; Belarusskaya Nauka: Minsk, Belarus, 2013 ; p. 221. (In Russian)

22. Rajasekhar, K.; Harendranath, C.S.; Raman, R.; Kulkarni, S.D. Microstructural evolution during solidification of austenitic stainless steel weld metals: A color metallographic and electron microprobe analysis study. Mater. Charact. 1997, $38,53-65$. [CrossRef]

23. Valiente Bermejo, M.A.; Wessman, S. Computational thermodynamics in ferrite content prediction of austenitic stainless steel weldments. Weld World 2019, 63, 627-635. [CrossRef] 